\title{
O conceito de informação imagética na Ciência da Informação: aproximações teórico-conceituais
}

\author{
Ana Cláudia de Araújo Santos \\ Doutoranda; Universidade Federal de Pernambuco, Recife, PE, Brasil; \\ anacllaudiasantos@gmail.com \\ Edvaldo Carvalho Alves \\ Doutor; Universidade Federal da Paraíba, João Pessoa, PB, Brasil; \\ edvaldocalves@gmail.com

\section{Henry Poncio Cruz de Oliveira} \\ Doutor; Universidade Federal da Paraíba, João Pessoa, PB, Brasil; \\ henry.poncio@gmail.com
}

\begin{abstract}
Resumo: As concepções acerca da informação passaram por mudanças ao longo dos anos de estudos que foram desenvolvidos para sua organização, uso e disponibilização. A partir desta asseveração, considera-se que esse processo de transformação foi fundamentado em ideias e pensamentos que perpassaram, fundamentalmente, os conceitos de documento e objeto de estudo da Ciência da Informação, a informação. Correntes teóricas e paradigmas foram construídos e reformulados, sobretudo, ao voltar-se para os documentos imagéticos. Nesse sentido, o presente artigo busca, a partir de uma pesquisa exploratória na Base de Dados de Periódicos em Ciência da Informação, apreender como vem sendo utilizado, no campo da Ciência da Informação, no Brasil, o conceito de informação imagética. Assim, assevera-se que essa ciência é construída por uma linguagem interna composta por seus códigos, métodos e técnicas, e percebe-se, com este estudo, que não há uma precisão conceitual para o entendimento de informação imagética na Ciência da Informação, pois não se constataram clareza e objetividade conceituais dessa terminologia. Ademais, sobreleva-se a necessidade e importância de se ampliar o escopo dessa pesquisa para estudos futuros a partir de análises dos anais de eventos científicos na área da Ciência da Informação e das bases de dados de teses e dissertações que não foram aqui contemplados.
\end{abstract}

Palavras-chave: Informação. Imagem. Ciência da Informação. Informação imagética. 


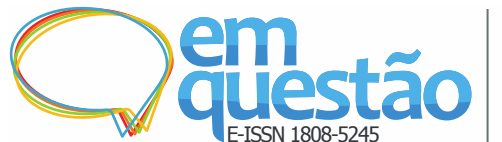

$O$ conceito de informação imagética na Ciência da Informação: aproximações teórico-conceituais

Ana Cláudia de Araújo Ssntos, Edvaldo Carvalho Alves e Henry Poncio Cruz de Oliveira

\section{Introdução}

A produção do conhecimento, a cada momento, torna-se intensa e crescente, e isso se reflete em um montante de documentos de várias tipologias: textuais, virtuais, tridimensionais e imagéticos ${ }^{1}$. Estes últimos, que sempre estiveram presentes na construção de um dado conhecimento, sempre receberam um tratamento diferenciado, sobretudo, em relação à leitura do seu conteúdo e ao tratamento de sua informação. As áreas do conhecimento se apropriaram da imagem de maneira diferenciada, o que também resultou em um conjunto de pesquisas sobre diversas abordagens da imagem.

Nesse contexto, destacam-se os estudos de Panofsky (1979), Smit (1996), Kossoy (2001) e Manini (2002), entre outros, que se debruçaram sobre o caráter polissêmico das imagens, buscando levantar questões sobre o seu estudo. Assim, alguns elementos como o conteúdo intrínseco, com ênfase no contexto histórico, (KOSSOY, 2001) passaram a ser de suma importância para a compreensão de um dado documento imagético. Ou ainda, o conjunto de dados técnicos para a elaboração de uma imagem, que pode ser entendido por dimensão expressiva (MANINI, 2002), de tal forma que o contexto histórico e as informações técnicas estão completamente imbricados. Isso resultou num variado conjunto de metodologias para descrição de acervos imagéticos, fator que merece destaque, pois vários elementos (métodos e ferramentas) passaram a descrever as imagens. Ressaltando-se que esses elementos nem sempre são de fácil interpretação, motivo pelo qual surgem questionamentos sobre como proceder à descrição de uma imagem e a análise do seu significado. Em muitas situações, esse processo era restrito apenas ao conteúdo informacional, ou conteúdo semântico, que são informações presentes na imagem, em detrimento da informação não visual (MANINI, 2002, p. 6).

Essas indagações e incômodos, como os salientados anteriormente, geraram vários trabalhos sobre a compreensão e interpretação da imagem na ciência; o foco desta pesquisa recai sobre a imagem na Ciência da Informação (CI). É pensando nessa ideia que surge a seguinte indagação: como a Ciência da Informação entende a informação contida nos documentos imagéticos, ou, dizendo de outra maneira, o que é informação imagética na CI? Com a intenção 
de conhecer e compreender tal conceituação, realizou-se uma pesquisa exploratória na Base de Dados Referenciais de Artigos de Periódicos em Ciência da Informação (BRAPCI) ${ }^{2}$ - utilizando como expressão para busca informação imagética (os critérios utilizados para essa busca serão apresentados na quarta seção) - com o propósito de identificar os autores e as conceituações elaboradas por eles acerca de tal temática.

A presente abordagem encontra-se distribuída em quatro seções de forma a possibilitar uma visão sobre a imagem na ciência, seus usos e tratamentos elaborados; apresenta também o escopo que compõe o trabalho e tece algumas considerações. Assim, propõe-se a contribuir para uma discussão sobre imagem, ciência e suas possíveis interpretações.

A primeira seção, Introdução, também composta pela subseção Percursos metodológicos, - expõe a temática, os objetivos, a problemática e os percursos realizados para fundamentar a discussão que aqui se apresenta. Em seguida, a segunda seção, Ciência da Informação: discursos e concepções, apresenta uma caracterização das transformações ocorridas em relação ao objeto de estudo da Ciência da Informação, a informação e os seus paradigmas, evidenciando as ideias de Thomas Kuhn (1998) com a definição de Revolução Científica. A terceira seção, $O$ tratamento da imagem na Ciência da Informação, traz à tona alguns estudos e discussões sobre a imagem na CI, sobrelevando os aspectos de uma longa tradição calcada numa tessitura textual.

Segue a quarta seção, Análise dos artigos selecionados na BRAPCI, que expõe as considerações sobre os artigos selecionados para a pesquisa em uma abordagem qualitativa com uma caracterização quantitativa, apresentando quadro, tabelas e gráficos sobre a informação imagética. E, por fim, nas Considerações finais, salienta-se que há uma imprecisão conceitual no conceito de informação imagética utilizado na Ciência da Informação, de maneira que os estudos selecionados são voltados para o tratamento e a disponibilização da informação contida nos documentos imagéticos. 


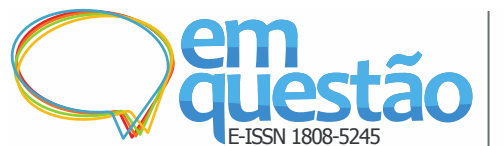

\subsection{Percursos metodológicos realizados}

A pesquisa realizada foi de cunho bibliográfico e teve uma abordagem descritiva e bibliométrica, em que se destacaram aspectos quantitativos, bem como a descrição de uma dada realidade com o objetivo de conhecê-la (GIL, 1991).

No campo de busca, selecionaram-se "todos os campos" - que incluem: autores; títulos, palavras-chave, resumo e referências - nesse campo se buscou por informação imagética. Feito isso, os arquivos foram salvos e uma nova busca pormenorizada foi realizada nos artigos de forma individualizada. Esse método possibilitou identificar em qual seção a palavra informação imagética foi referenciada e qual o contexto em que estava sendo aplicada.

A etapa seguinte foi a distribuição e organização das informações em tabela e gráfico objetivando sua disposição estrutural. Na sequência procedeuse à leitura pormenorizada de cada artigo e à elaboração do resumo com vistas a correlacionar o conteúdo que tinha sido construído pelos autores dos referidos documentos.

Essas interpretações podem ser apreciadas na seção análise dos artigos selecionados na BRAPCI, em que os dados levantados serão discutidos. Os indicadores selecionados foram: ano de publicação, vínculo institucional e região do Brasil, todos a partir do nome do primeiro autor de cada um dos artigos.

\section{Ciência da Informação: discurso e concepções}

A Ciência da Informação ao longo do seu desenvolvimento passou por várias transformações e mudanças de concepções em relação ao seu objeto de estudo: a informação. Essas questões trazem à tona a própria reflexão sobre a consolidação da CI enquanto ciência e sobre suas abordagens.

De maneira, geral, é possível descrever três tipos de conceitos que foram elaborados pelos diversos cientistas da informação, a saber: 1) o primeiro conceito de informação na Ciência da Informação é mais restrito e está 
vinculado à sua dimensão material, física, sendo o fenômeno estudado a partir de uma perspectiva quantitativa e positivista (ARAÚJO, 2014). A essa definição associa-se o paradigma físico voltado para uma visão e abordagem mais tecnicista da informação, que estava orientada para os sistemas de informação, não havia preocupação com o ser social.

Como a ciência é o reflexo das interações e modificações sociais, uma nova concepção surge e toma corpo, podendo ser denominado de segundo conceito:

2) “[...] um pouco mais amplo voltado para a dimensão cognitiva, sendo informação algo associado à interação entre dados (aquilo que existe materialmente) e conhecimento (aquilo que está na mente dos sujeitos), e seu estudo relacionado à identificação de significados, interpretações [...]" (ARAÚJO, 2014, p. 70).

Ou novamente, se associa ao que foi denominado de paradigma cognitivo, em que o indivíduo passa a ter certa importância, devido ao seu conhecimento individual e à sua necessidade.

E, por fim, um novo conceito mais atual: 3) que reflete "[...] as tendências contemporâneas que implicam um grau maior de complexidade e abstração, com a inserção da informação no escopo da ação humana e no âmbito de contextos socioculturais concretos [...]" (ARAÚJO, 2014, p. 70), relacionado com o paradigma social, considerando as necessidades de conhecimento construído e compartilhado entre indivíduos.

Diante do exposto, nota-se que houve uma quebra de pensamento e paradigmas (concepções), em relação à ideia conceitual acerca da informação e das necessidades que os indivíduos passaram a ter quando de sua busca. Como dito, essas transformações são reflexos sociais, pois o que estava posto não atendia mais à necessidade real dos agentes sociais. Ao analisar as ideias de Kuhn (1998), percebe-se que a Ciência da Informação viveu uma Revolução Científica - mudanças significativas de concepções teóricas em que o pensamento vigente é posto em questionamento -, passando por momentos de construção e reconstrução de seu objeto de estudo (KUHN, 1998).

Dessa forma, há uma dinamicidade na construção dos saberes, que reflete a própria dinamicidade cultural a que todos estão submetidos, cientistas 
ou não. Por isso "a ciência busca, essencialmente, desvendar e compreender a natureza e seus fenômenos, através de métodos sistemáticos e seguros. No entanto, face à dinamicidade intrínseca à própria natureza, seus resultados são sempre provisórios" (TARGINO, 1998, p. 2). Desse modo, "sem pretensões históricas, infere-se que a ciência influencia há séculos a humanidade, criando e alterando convicções, modificando hábitos, gerando leis, provocando acontecimentos, ampliando de forma permanente e contínua as fronteiras do conhecimento" (TARGINO, 1998, p. 2).

Nessa perspectiva, as áreas científicas são construídas no seio da sociedade e atendem às necessidades que dela emanam. A Ciência da Informação é uma área científica voltada para as necessidades informacionais dos indivíduos organizados em sociedade:

[...]a Ciência da Informação é um campo dedicado às questões científicas e à prática profissional voltadas para os problemas da efetiva comunicação do conhecimento e de seus registros entre os seres humanos, no contexto social, institucional ou individual do uso e das necessidades de informação(SARACEVIC, 1996, p. 47).

Outro ponto de grande destaque que marcou um momento de profunda mudança na CI foi a compreensão do conceito de documento, durante muito tempo restrito aos registros escritos. De tal forma que não atendia mais à real produção da diversidade do conhecimento humano, pois este era refletido em vários suportes. Nesse aspecto, sobrelevam-se as contribuições dos estudos de Otlet (1934), Ortega e Lara (2008), Smit (2008), e Torres Almeida (2013), para o alargamento da definição de documento, incluindo as representações imagéticas, entre elas, a fotografia. Corroboram com esse pensamento outros pesquisadores como Briet (1951) e Buckland (1991), que darão a tônica para as especificidades de um documento, com ênfase maior na sua evidência e a interpretação que o pesquisador faz do mesmo. 


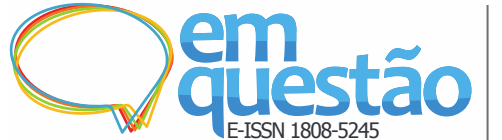

$O$ conceito de informação imagética na Ciência da Informação: aproximações teórico-conceituais

Ana Cláudia de Araújo Ssntos, Edvaldo Carvalho Alves e Henry Poncio Cruz de Oliveira

\section{O tratamento da imagem na Ciência da Informação}

Diante do exposto nas seções anteriores, nota-se que os profissionais da Ciência da Informação passaram a debruçar-se sobre os vários tipos de documento e a desenvolver estudos para organizá-los e disponibilizá-los ao público.

O livro A imagem em Ciência da Informação, organizado por Sousa, Fujita e Gracioso (2014), compõe-se de um conjunto de textos que versam sobre o tratamento da imagem na CI. Na apresentação, as autoras evidenciam que ainda há muito o que ser feito para que seja dada a atenção devida aos documentos imagéticos, uma vez que a Ciência da Informação ainda não os reconhece como sendo documentos (SOUSA; FUJITA; GRACIOSO, 2014).

Nessa obra, os autores dos trabalhos discutem sobre a construção de um conhecimento que se deu por documentos imagéticos, destacando os filmes, os livros e as fotografias. Nesse sentido, fica evidente o caráter de não cientificidade que tais documentos adquiriram e, de certa forma, o fato de que não foi explorado o seu caráter informacional. Assim, é possível afirmar que a informação visual passou a constituir-se num obstáculo tanto para os pesquisadores como para os usuários das unidades de informação, pois "o problema reside justamente na sua resistência em aceitar, analisar e interpretar a informação quando esta não é transmitida segundo um sistema codificado de signos em conformidade com os cânones tradicionais da comunicação escrita." (KOSSOY, 2001, p. 30). Isso também abre uma perspectiva para a questão da representação dos documentos imagéticos, ou seja, a transmutação de uma linguagem estritamente visual para uma linguagem verbal, o que ocasionou o desenvolvimento de metodologias para a organização da informação em documentos imagéticos.

Vale salientar que esses estudos se voltam para o tratamento das imagens que são produzidas por aparelhos técnicos - fotografias e vídeos - e por construções manuais: as pinturas. Assim, o tratamento que mais se destaca na área da Ciência da Informação está no campo da organização da informação; ainda são incipientes os trabalhos que entendem os documentos imagéticos como canal de comunicação, e, sobretudo, comunicação científica. ${ }^{3}$ 
Para Maimone e Talámo (2008, p. 1), “a Ciência da Informação, como área do conhecimento que estuda e aplica processos de organização e representação da informação, deteve-se prioritariamente nos documentos impressos". Essa situação também se fez presente em outras áreas, como, por exemplo, na História, que teve a construção do seu conhecimento calcada basicamente em documentos escritos, revelando, assim, sua tradição livresca (KOSSOY, 2001).

Convém ressaltar que, as áreas do conhecimento passam a evidenciar a importância dos documentos imagéticos, como destacam Maimone e Talámo (2008, p. 1), ao afirmar que:

[...]os documentos imagéticos, embora tenham crescente presença e importância social evidente, tornam-se objeto de tratamento mais tardiamente, tornando urgente a criação de metodologias específicas segundo tipologias documentárias que vão se constituindo à medida que avança essa discussão.

A situação referenciada pelas autoras sinaliza a presença constante dos documentos imagéticos na vida social, como um produto de consumo universal, mas que ainda no campo científico, se apresentam como incipientes os estudos voltados para o tratamento informacional das imagens.

\section{Análise dos artigos selecionados na BRAPCI}

A pesquisa realizada na Base de Dados Referenciais de Artigos de Periódicos em Ciência da Informação possibilitou o levantamento de sete arquivos, a partir da expressão informação imagética. Os trabalhos foram publicados por pesquisadores entre os anos 2004 e 2016, contudo, há um intervalo, que varia entre um a quatro anos, entre uma publicação e outra, como pode ser visualizado no quadro, a seguir.

Quadro 1 - Levantamento realizado na Base de Dados Referenciais de Artigos de Periódicos em Ciência da Informação - (BRAPCI)

\begin{tabular}{|l|l|c|}
\hline \multicolumn{1}{|c|}{ Título } & \multicolumn{1}{|c|}{ Autor (es) } & Ano \\
\hline $\begin{array}{l}\text { \#impeachment ou \#naovaitergolpe: } \\
\text { uma análise sobre a folksonomia na } \\
\text { indexação de imagens fotográficas em } \\
\text { redes sociais da Web 2.0 }\end{array}$ & MANINI, Miriam Paula. & 2016 \\
\hline Análise da informação imagética: & GONÇALVES, Eveline Filgueiras; & 2016 \\
\hline
\end{tabular}




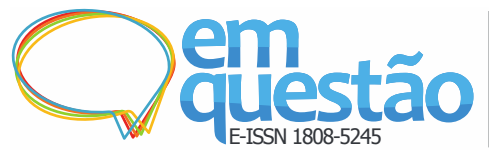

uma abordagem sob a perspectiva cognitiva

Pós-Fenomenologia e Ciência da Informação: aportes epistêmicos para acesso ao conhecimento

Metodologias de representação da informação imagética

Tratamento informacional de imagens artístico-pictóricas no contexto da Ciência da Informação

Representação temática de imagens: perspectivas metodológicas

A Representação de Imagens no Acervo da Biblioteca Digital Paulo Freire - proposta e percursos
O conceito de informação imagética na Ciência da Informação: aproximações teórico-conceituais Ana Cláudia de Araújo Ssntos, Edvaldo Carvalho Alves e Henry Poncio Cruz de Oliveira Fonte: Dados da pesquisa (coleta de dados na BRAPCI).

Em relação à autoria, quatro publicações $(57,14 \%)$ foram escritas por dois autores (autoria dupla), seguindo-se a autoria tripla, com duas publicações $(28,58 \%)$, e a autoria simples, com apenas uma publicação (14,28\%). Ainda em relação à produção no período de 2004 a 2016, identificou-se que cinco autores publicaram artigos sobre imagem e sua organização, havendo incidência maior de autores que publicaram somente um trabalho (80\%). Apenas uma autora (20\%), Maimone (2007; 2008; 2009), publicou três artigos, juntamente com outros pesquisadores. É possível deduzir que, no referido período, não houve muitos trabalhos sobre a informação imagética que estejam indexados na base da BRAPCI.

Em relação ao quantitativo de publicações por região, a maioria dos trabalhos é da Região Sudeste, com o total de quatro trabalhos $(57,14 \%)$ representados pelas instituições localizadas nos estados de São Paulo (USP) e Rio de Janeiro (IBICT); em seguida, tem-se a Região Nordeste com dois trabalhos (28,58\%), ambos da Universidade da Paraíba (UFPB); e, por fim, a Região Centro-Oeste com um trabalho $(14,28 \%)$, da Universidade Brasília (UNB). Esse indicador, possibilitou identificar a área geográfica que se destacou na produção de estudos sobre a informação imagética, sinalizando uma produção contínua sobre a temática.

No que tange ao tipo de vínculo institucional, o que mais se destacou foi o estudantil (42,86\%), enquanto que o de docente e bibliotecária obtiveram $28,57 \%$, cada. O vínculo estudantil pode ser subdividido em graduação e pós- 
graduação (mestrado e doutorado), sendo os dois últimos de Pós-Graduação acumulados pela mesma autora.

Como dito anteriormente, Maimone foi uma das autoras que mais produziram durante o período pesquisado. Ela teve dois vínculos estudantis, nos anos de 2009 e 2007, ambos em Pós-Graduação em Ciência da Informação, doutorado e mestrado, respectivamente, enquanto que no ano de 2008 atuou como professora na área de Biblioteconomia, como consta na representação abaixo:

Figura 1 - Mapa conceitual da produção de Maimone (2007-2009)

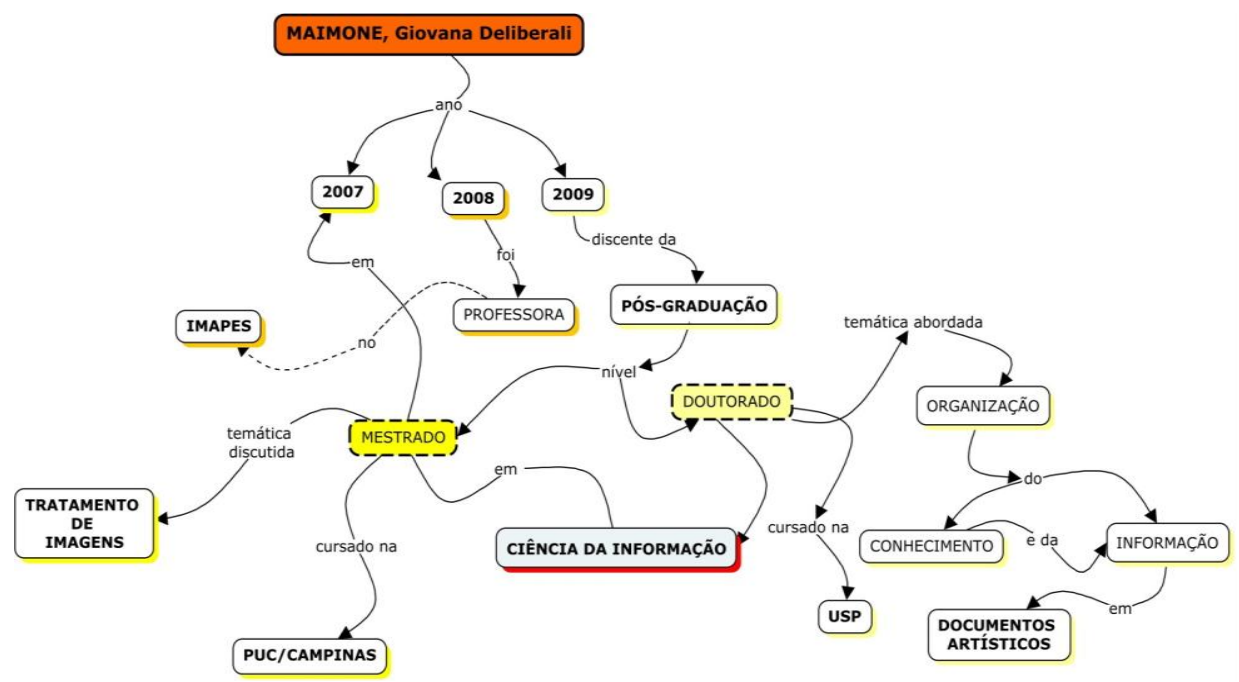

Fonte: Dados da pesquisa (coleta de informações no Currículo Lattes).

Ressalta-se também que no período em que publicou os artigos que fazem parte do escopo desta pesquisa, a autora dedicava-se aos estudos sobre imagem, sua representação e organização, como pode ser notado nas produções de sua dissertação e tese.

Todos os trabalhos listados acima encontram-se publicados em periódicos, em Ciência da Informação, contemplando sete deles, a saber: Biblionline, Em Questão, Incid, Transinformação, DataGramaZero, Informação \& Informação e Ciência da Informação. Cada um destes representa 14,28\% da publicação dos artigos, ou seja, um artigo em cada periódico listado. Quando correlacionados, os indicadores vínculo institucional e periódicos em CI, percebe-se que não houve a endogenia acadêmica, uma vez que cada autor 
publicou em periódicos diferentes da sua afiliação institucional, independente se estudantil ou profissional.

Destaca-se também que todos os trabalhos são resultados de pesquisas desenvolvidas a partir de projetos aprovados por instituição de fomento ou da realização de pesquisas científicas no âmbito dos Programas de Pós-Graduação brasileiros, todos eles relacionados a uma das tipologias de imagem, entre elas, fotografia e pintura.

No que se refere ao conteúdo abordado nos documentos selecionados, passa-se à seguinte análise descritiva individualizada, agrupadas em duas categorias: a) recuperação da informação e b) representação da informação.

A categoria recuperação da informação foi contemplada com dois artigos, a saber: o primeiro, \#impeachment ou \#naovaitergolpe: uma análise sobre a folksonomia na indexação de imagens fotográficas em redes sociais da Web 2.0, de Nóbrega e Manini (2016), apresenta um estudo de caso sobre a atribuição de palavras-chave, denominadas de tags ou etiquetas, ao conteúdo de imagem relacionado à temática do impeachment, por usuários de duas redes sociais: Flickr e Instagram. As autoras compreendem que, a partir da Folksonomia, o usuário pode acessar, tratar e organizar a informação usando seu próprio vocabulário e de forma livre e colaborativa. Segundo as autoras, isso traz um desafio para a Ciência da Informação, considerando dois aspectos: 1) a própria dificuldade para a análise informacional das imagens, devido o seu aspecto polissêmico e subjetivo com forte apelo sensorial; e 2) alguns questionamentos sobre a eficácia da Folksonomia na descrição, representação e recuperação dos conteúdos imagéticos. Acreditam que, ao identificar os padrões de etiquetagem dessas redes, será possível analisar seu potencial como método de representação da informação imagética e seu impacto na construção da memória coletiva. Para as autoras, as imagens fotográficas se tornaram objeto de estudo da CI a partir do reconhecimento do seu valor informativo e documental, entendendo o estudo do tratamento informacional de documentos imagéticos como um dos mais complexos da área, devido ao caráter polissêmico das imagens.

Seguindo o referencial teórico de maior relevância na CI para as propostas de metodologia que visam contornar o aspecto subjetivo da imagem, 
basearam-se nos níveis de compreensão da imagem de Panofsky (1979), pela contribuição teórica para indexação de imagens a partir da distinção dos três níveis de conteúdo com base na iconologia e na iconografia. As autoras acreditam que a teoria da Dimensão Expressiva, de Manini (2002), amplia os métodos tradicionais, ao considerar também os níveis de produção da imagem, preocupando-se com a recuperação visual com base na técnica. Em relação à abordagem da Folksonomia, utilizam os estudos de Cañada (2006) sobre as motivações e os benefícios da etiquetagem para a recuperação da informação, os quais constataram a existência de alguns padrões e estilos classificados como egoísta, amigável, altruísta e populista. Por acreditarem que a informação imagética tem uma relação diferenciada com a construção da memória pela associação natural da lembrança a uma imagem mental, Nóbrega e Manini (2016) identificam, com base nas ideias de Le Goff (1990) e Bittencourt (1998), a imagem fotográfica como um potencializador da memória coletiva; assim, a partir da utilização das tags no universo da web 2.0, e por meio da Folkosonomia, estas podem ser uma forma de compartilhamento dessa memória.

As autoras utilizam como metodologia a análise e classificação das etiquetas que indexam cada imagem selecionada, a partir dos níveis de conteúdo das imagens de Panofsky (1979), da Dimensão Expressiva de Manini (2002) e dos estilos de etiquetagem de Cañada (2006). Também buscam estabelecer relações dos padrões de etiquetagem com a construção da memória coletiva referente ao momento social e histórico vivido pelos brasileiros. Para análise dos resultados, tomam como base a importância do fator envolvimento na construção e na evocação da memória identificada por Halbwachs (2006), associando-a a fatores como interesse e motivação, acreditando que "se há interesse em um momento, há motivação para se inserir no mesmo de maneira mais aprofundada, gerando envolvimento" (NÓBREGA; MANINI, 2016, p. 79). Assim, utilizam os estilos de etiquetagem de Cañada (2006) com motivação mais elevada para verificar se estes são predominantes nos padrões identificados.

Nóbrega e Manini (2016) concluem que o padrão de etiquetagem com base no nível iconológico de compreensão da imagem, no Flickr, é de estilo 
altruísta; e, no Instagram, o padrão é de estilo populista. Ainda com base no nível iconológico de compreensão de imagem, o padrão geral de etiquetagem das redes sociais de imagens levantadas é de estilo altruísta.

As autoras constatam que a Folksonomia pode ser tida como um recurso conveniente para a representação da informação imagética no âmbito das redes sociais e de outros ambientes da Web 2.0, pois indica que - mesmo considerando diversas associações com contextos intrínsecos à imagem e ao próprio usuário - as comunidades das redes sociais ainda têm a preocupação com a recuperação do conteúdo. Nóbrega e Manini (2016) afirmam também que essas etiquetagens não devem ignoradas, pois futuramente podem tornar-se importante fonte de informação para a pesquisa historiográfica. Logo, devem ser estudadas para que se possa ter domínio sobre elas, garantindo a disponibilidade e acesso às tags a longo prazo. Acreditam ser uma tarefa da CI acompanhar e conhecer esse novo tipo de informação, que é representado pela Folksonomia, visando explorar todas as suas potencialidades.

Em vista do exposto, considera-se que, ao abordar a informação imagética, as autoras fazem referência às imagens fotográficas, mas não apresentam uma conceituação para a expressão informação imagética.

Seguindo a análise da categoria temática recuperação da informação, o segundo artigo, Pós- Fenomenologia e Ciência da Informação: aportes epistêmicos para acesso ao conhecimento, de Figueiredo (2012), baseia-se na argumentação de que os estudos sobre as mídias e tecnologias digitais ainda são muito recentes e carentes de uma base epistemológica. Assim, elege a PósFenomenologia como fundamento necessário para a compreensão dos usos de imagens de função informativa pela ciência, tendo em vista que este enfoque investiga o uso das tecnologias e de instrumentos como elemento mediador entre o sujeito e o mundo. Apesar de considerar que o uso da imagem epistêmica é antigo, a autora acredita que uma novidade nas ciências modernas é a informação imagética produzida por tecnologias e disponibilizada na web.

Buscando desenvolver essa reflexão, Figueiredo (2012) referenciou alguns princípios da Fenomenologia como pressuposto teórico para o uso da Pós-Fenomenologia no acesso à informação imagética, como a corrente desenvolvida por Merleau-Ponty, baseada em estudos sobre o corpo e a 
percepção. Segundo a autora, a contribuição da fenomenologia à CI é a ideia de que não é possível definir uma percepção e uma observação "puras" do mundo, sendo estas sempre mediadas.

Como aporte teórico sobre a Pós-Fenomenologia, utilizou a obra de Don Ihde (2004) por oferecer uma taxonomia que dá conta das relações entre o homem e a tecnologia, que pode dar fundamentos aos estudos recentes da CI. Destacam-se três abordagens: (1) corpo tecnológico - é entendido como uma terceira dimensão que assume e expande as teorias sobre o corpo emotivo - que perpassa o corpo perceptivo e o corpo que experimenta, de Merleuau-Ponty e Foucault; (2) aquisição do conhecimento científico pela utilização das tecnologias; (3) perspectiva visualista da ciência, que exclui os outros sentidos e privilegia a visão reduzindo-a a um estilo objetivado. Esse visualismo, para Ihde, constitui-se em um hábito cultural que adquiriu uma posição confortável; ele faz uma crítica, considerando que, se todas as percepções do corpo fossem utilizadas, se teria um resultado mais completo (FIGUEIREDO, 2012).

Para Figueiredo (2012), os estudos de Ihde conciliam o:

[...] uso de instrumentos na ciência para mediar o acesso a conhecimentos com a predominância do uso de imagens no meio científico em comparação a outras percepções que caíram em desuso com o passar dos anos, o olfato e o tato, por exemplo (FIGUEIREDO, 2012, p. 32).

Essa noção contribuiu para o entendimento proposto, no trabalho, sobre a produção e o acesso ao conhecimento mediados por máquinas, visto que demonstrou que existe uma ampliação dos sentidos através da mediação tecnológica, dando mais importância à participação da tecnologia no processo de produção do conhecimento. Conclui que a Pós-Fenomenologia pode subsidiar epistemologicamente os estudos sobre o uso das tecnologias com apropriação e busca da informação, "sobretudo das imagens de viés informativo para o usuário" (FIGUEREIDO, 2012, p. 34).

Cabe destacar que o texto, apesar de buscar fundamentos epistemológicos para a CI, trouxe apenas aportes para discutir e demonstrar a importância da tecnologia como mediadora nos processos científicos e na relação do homem com o mundo. Todavia, abordou funções para as imagens como as epistêmicas e as informativas, mas não especificou o que seriam. E, 
apesar de utilizar o termo informação imagética, esta também não foi conceituada.

A segunda categoria temática, representação da informação, composta por cinco artigos apresenta algumas considerações, conforme se demonstra na sequência. No primeiro artigo, Representação temática de imagens: perspectivas metodológicas, de Maimone e Gracioso (2007), as autoras discutem sobre o tratamento de imagens e sua representação, utilizando-se metodologias específicas para esse tipo de suporte informacional. Apresentam um referencial básico de autores de renome na área da Ciência da Informação, entre eles, Panofsky (1979), Smit (1996) e Manini (2002), cuja discussão versa sobre o conjunto de informações que compõe as imagens e as fotografias, com ênfase nas informações extrínsecas e intrínsecas desses documentos (MAIMONE; GRACIOSO, 2007).

Nesse mesmo artigo, as autoras utilizam a metodologia que foi desenvolvida por Manini (2002) para aplicar em um conjunto de quadros de Salvador Dalí. A escolha dessa metodologia está relacionada ao fato de as autoras entenderem que é a mais completa, e contempla as informações necessárias para a representação de imagens, entre elas a dimensão expressiva (especificação do tipo de obra, no caso em questão, óleo sobre tela) (MAIMONE; GRACIOSO, 2007).

Ao realizar suas considerações, Maimone e Gracioso (2007) destacam que algumas informações não foram preenchidas, por exemplo, o onde específico, por não saberem e não conseguirem identificar qual o nome do local que foi representado na pintura. Também salientam a necessidade do levantamento de informações sobre o autor e sua escola artística para a indexação e representação da obra. Finalizam enfatizando que o trabalho contribui para o tratamento de imagens que se encontram disponibilizadas na web.

O segundo artigo, elaborado um ano após a publicação do artigo anterior, Maimone e Tálamo (2008), em Tratamento informacional de imagens artístico-pictóricas no contexto da Ciência da Informação, discutem o processo de tratamento informacional como agente potencial de geração do 
conhecimento. Compreendem que a informação só pode ser tratada após ser registrada, e que esses registros materiais necessitam de metodologias específicas às suas características peculiares. Abordam esse processo a partir do contexto da informação imagética com ênfase nas imagens artístico-pictóricas (pinturas).

As autoras contextualizam, a partir da ótica cognitiva, que a informação é uma solução para corrigir uma anomalia do conhecimento, sendo imprescindível a ação de leitura para a apropriação e construção de sentidos, o que requer uma "preciosa acuidade" na maneira de representá-la (MAIMONE; TÁLAMO, 2008, p. 2). Compreendem a imagem artístico-pictórica como uma metarrepresentação, já que se apresenta como uma representação do mundo do artista, e permite, através da decodificação de suas mensagens, interpretar o contexto sócio-histórico de produção.

Maimone e Tálamo (2008) argumentam que a passagem dos códigos visuais presentes na imagem para uma linguagem verbal só se concretiza com metodologias de análise e indexação de conteúdo, o que demanda do documentalista, além da tarefa de converter a matéria e conteúdo em informação recuperável, também o domínio teórico-conceitual dos repertórios sociais que subsidiam essa conversão.

Por fim, apresentam o fluxo informacional, a partir do sistema de recuperação da informação, constituído de três estados: o conhecimento registrado, o sistema informacional e o usuário. Ou seja, o documento, depois de operações intelectuais de análise e representação do seu conteúdo, que estão reunidos nos sistemas informacionais, é disponibilizado para o acesso dos usuários, para quem o sistema foi estruturado. Esse processo é concretizado pela linguagem documentária, que consiste em estruturação de esquemas linguísticos com a função de tratar o conhecimento, dispondo-o como informação.

Maimone e Tálamo (2008) chegam à conclusão de que para a adequada comunicação e recuperação dos documentos é importante o tratamento do seu conteúdo informacional, acreditando que a análise das características das imagens permite entender, de forma mais clara, o modo como essas imagens podem ser trabalhadas para sua efetiva recuperação. 
No terceiro artigo, Metodologias de representação da informação imagética, Maimone e Tálamo (2009) revisitam a literatura existente sobre as metodologias para representação da informação imagética, e propõem uma adaptação da metodologia de Augustín Lacruz (2006) para aplicação nas pinturas em museus (no caso apresentado, os museus paulistas). Assim, demonstram a existência de um atraso nas pesquisas em relação à representação da informação imagética em comparação com as pesquisas sobre a representação de outros documentos, entre eles, os textuais. Argumentam que existe uma necessidade de representar informação tanto de cunho descritivo quanto temático, para a recuperação de informações de imagens.

Partindo da consideração de que "as formas (procedimentos) adotadas para indexação de imagens configuram-se numa metodologia, pois determinam 'modos' de execução de tarefas, pressupondo a 'orientação' por métodos de raciocínio lógico.” (MAIMONE; TÁLAMO, 2008, p. 182), as autoras abordam rapidamente três metodologias de representação, no cenário nacional, que utilizam a indexação para representar o conteúdo dos documentos imagéticos: a primeira, de Smit (1987), aborda a descrição dos objetos orientada por perguntas - quem, onde, quando, o que e como; a segunda metodologia é a utilizada pela Biblioteca Nacional para fotografias e consiste em uma pesquisa do conteúdo geral da imagem enfatizando o aspecto histórico; e a terceira identificada, de Manini (2002), consiste no tratamento informacional de fotografias integrando a Dimensão Expressiva da Imagem.

Em âmbito internacional, Maimone e Tálamo (2009) destacam que a metodologia elaborada por Agustín Lacruz (2004) baseia-se tanto na análise de conteúdo como na representação documentária (resumos, documentários, os descritores categorizados e normalizados e a compilação das fontes bibliográficas consultadas) e está estruturada em cinco etapas sucessivas catalogação, análise de conteúdo, descrição, identificação e interpretação.

Considerando a problemática identificada pelas autoras quanto ao fato de os museus paulistas não realizarem o tratamento documentário com as proposições explicitadas na metodologia de Agustín Lacruz (questões relacionadas sobretudo a fatores socioeconômicos), Maimone e Tálamo (2009) 
propõem uma metodologia menos exaustiva, mas que segue os princípios apresentados por Agustín Lacruz (2004), para ser aplicada às pinturas, em contexto brasileiro.

Diante do exposto, evidencia-se que as autoras não conceituam informação imagética, deixando expressamente claro que o objeto tratado, no artigo, são as pinturas ou as imagens artísticas, restringindo-se, assim, a essa tipologia documental e não referenciando outros documentos iconográficos. A preocupação da pesquisa orienta-se para o tratamento informacional de imagens pictóricas. Desse modo, realizam a adaptação de uma metodologia para auxiliar, de forma prática, no tratamento e na representação informacional das imagens, assim como em alguns procedimentos documentários, enfatizando a importância da aplicação de uma linguagem documentária.

$\mathrm{O}$ artigo Análise da informação imagética: uma abordagem sob a perspectiva cognitiva, o quarto da categoria temática representação da informação, escrito por Gonçalves, Oliveira e Neves (2016), desenvolve-se a partir de uma pesquisa de cunho bibliográfico sobre a relação disciplinar entre a Ciência da Informação (CI) e as Ciências Cognitivas (CG), concernente ao processo de recuperação da informação, em específico às contribuições para a representação conceitual de imagens. Os autores preocupam-se em explicar como a polissemia das imagens, em uma abordagem cognitiva, pode interferir no tratamento a partir de indexadores e na busca realizada pelos diversos usuários.

Utilizam como referencial as conceituações das CG sobre cognição, entendendo-as como o ato de conhecer que se refere à mente e seus processos. Esses processos como memória, percepção, associação, abstração, entre outros, são identificados pelos autores como alvo de interesse da CI, pois demonstram a quantidade de aspectos que interferem no modo como um indivíduo analisa uma imagem, suscitando problemas para a indexação de imagens.

De acordo com os autores, a representação é uma capacidade cognitiva que reflete o uso da linguagem e pode tanto ser verbal como não verbal. Utilizando como referencial a definição de Sternberg (2000), consideram que a Representação do Conhecimento se relaciona com os métodos da representação da informação imagética, pois envolve imagens e preposições, visto que são 
com palavras que as fontes não textuais são indexadas. . A partir disso, identificam os principais problemas da área, pois apesar de a representação mental do conhecimento realizar-se por meio de palavras ou imagens, nenhuma traz todas as características daquilo que está sendo representado. Além disso, baseando-se nas hipóteses elaboradas por Paivio (1969), Anderson e Bower (1974) e Finke (1991), os autores mostram que a forma de representar o conhecimento imagético está baseada na imaginação, sendo que esta é a representação mental do conhecimento imagético, simbólico e daquilo que foi compreendido pelos sentidos de cada indivíduo.

Os autores afirmam que alguns estudiosos da área já entenderam que a indexação de documentos imagéticos exige muito mais do que os antigos métodos de indexação textual. Referenciam autores como Manini $(2001,2002)$ e Rodrigues (2007), que tentaram metodizar os processos de indexação de imagens. Contudo, argumentam que a característica polissêmica dificulta o alcance de um padrão, pois pode resultar em um "conflito entre o interesse do indexador e o do usuário" (GONÇALVES; OLIVEIRA; NEVES, p. 121, 2016). Contrapondo-se a Manini (2002), os autores afirmam que, em uma abordagem cognitiva, todo o repertório intelectual do indexador interferirá diretamente no modo como as ideias serão evocadas, por meio da associação, para identificar o conteúdo intelectual que uma imagem pode representar.

Também são abordados os autores e as teorias sobre o estudo da representação do conhecimento imagético, tais como: Lancaster (2004) e a representação temática; Panofsky (1979) e a teoria da análise iconológica; Shatford (1984); Smit (1996); Lacerda (1993); Manini (2002) e Barros (2012). Os autores do artigo em pauta compreendem que essa representação começa na leitura do documento, sendo uma atividade cognitiva. Para eles, é com base na percepção que as impressões sensoriais são organizadas e interpretadas, atribuindo a essas significados. Eles concluem que é possível fundamentar a capacidade imaginativa para uma adequada representação do conhecimento. Em resumo, acreditam que a análise da informação imagética resulta da triangulação entre o referente, a capacidade imaginativa e a interpretação, e é fundamentada nos aspectos cognitivos, pois abrange a dimensão expressiva, as informações denotativas e as conotativas. 
Concluem que existe grande leque de possibilidades de estudos relacionados à cognição humana e suas implicações para a CI, e indicam que, no caso da representação da informação imagética, devem contemplar os estudos específicos e aplicados a cada processo mental e suas capacidades, para assim buscar formas práticas de metodologias de análise.

Desse modo, verifica-se que, apesar de identificarem informação imagética como não texto, os autores não especificaram nem conceituaram informação imagética, tendo os exemplos centrados em fotografias.

Por fim, o quinto artigo da categoria temática representação da informação, A representação de imagens no acervo da Biblioteca Digital Paulo Freire $(B D P F)$ - proposta e percursos, de Azevedo Netto, Freire e Pereira (2004), busca construir um corpus teórico - metodológico para o tratamento e a recuperação das informações imagéticas do acervo da Biblioteca Digital Paulo Freire. Seus autores destacam que, somente a partir de um novo paradigma do conhecimento, a imagem passa a ser tratada como um significativo repositório de informação, sendo incorporada pelo paradigma estético. No entanto, as várias naturezas da informação demandam necessidades específicas para seu tratamento e organização, que antes eram realizados em determinadas instâncias - museu, arquivo e biblioteca. Mas as novas tecnologias de informação e da comunicação possibilitaram que um mesmo acervo possuísse documentos de naturezas diversas, demandando uma gama maior de instrumentos teóricopráticos para o tratamento da informação nos mais variados suportes e gêneros.

Os autores fundamentam seu referencial teórico na semiótica, estética e teoria da arte; assim, consideram que o termo imagem possui um sentido polissêmico, perpassando todos os campos do conhecimento humano, como o religioso e o artístico, os quais também o utilizam em variados sentidos. Afirmam que a "conceituação de imagem deve ser considerada diversa", tendo em vista o caráter diferenciado de suas mídias e os modos distintos de apresentação, permanência e ação. Adotam no estudo a noção de imagem como algo restrito aos registros - fotografias e vídeos - de ações e eventos, de quaisquer origens ou suportes sobre a temática principal da BDPF, dentro da esfera da estética (ou da forma) (AZEVEDO NETTO; FREIRE; PEREIRA, 2004). 
Para os autores, a noção de imagem desencadeia variações múltiplas de funções e significados; como exemplo citam as categorias propostas por Aumont (1995) para diferenciar tais usos: simbólico, epistemológico e estético. Buscando adotar na pesquisa um núcleo comum que integre essas significações, conceituam imagem como "um artefato que intercede à relação do homem consigo próprio e com o mundo a sua volta, como modo de produção de sentido" (AZEVEDO NETTO; FREIRE; PEREIRA, 2004, p. 19). Essa conceituação fundamenta-se na teoria da representação de Santaella e Nöth (1998), que auxilia na criação de um vínculo comum entre todos os tipos de imagens, registrando o termo imagem como algo que produz significados, gerando novos sentidos pelo processo da interpretação mental e de empréstimo do real favorecendo a constituição de novas imagens, criando um ciclo infinito de significação. Dessa forma, entendem imagem como um fenômeno de significação e comunicação, portanto conteúdo de atividade semiótica.

Concluem que a imagem, enquanto ato de representação, pode ser abordada a partir de diferentes níveis de análise relacionados à natureza e à abrangência da informação pretendida. Por isso recorrem a Panofsky (1979) e sua distinção dos níveis informativos da imagem, bem como a Azevedo Netto (1998), para desenvolver o entendimento sobre a informação imagética contida no acervo da BDPF tendo em vista a categorização de informação técnica, informação estética, informação espacial e informação relacional; e a Smit (1996) por este considerar imagem como uma entidade tripartida, composta de suporte, expressão imagética e conteúdo informacional, e assim definir os termos a serem utilizados para a identificação dos atributos - genéricos e específicos - do acervo imagético da BDPF. A proposta metodológica tem como ponto central a flexibilidade, visando adequar-se às peculiaridades e contorno do objeto, e fundamenta-se em Becker (1993), na teoria semiótica de Peirce (1985), entre outros. Objetivando a recuperação da informação, pautamse na Ciência da Informação e na "análise de conceitos", tendo Dahlberg (1978) e Hjørland e Albrechtsen (1995) como principais referências. Para construir um sistema de recuperação da informação, utilizam como fundamento Foskett (1973). 
Os autores buscam fundamentar e definir os conceitos epistemológicos utilizados, como imagem e informação imagética, recorrendo a outras áreas como semiótica, teoria da arte e estética. Tomando o caráter polissêmico do termo, buscam precisar sua utilização no âmbito do projeto, e assim propor princípios de representação condizentes para a extração das informações potenciais do suporte imagético.

Observando a análise dos artigos ora exposta, nota-se que, embora não haja uma conceituação para informação imagética nos artigos supracitados, todos os autores se referem a um tipo específico de informação que está contida nas imagens, seja nas fotografias ou nas pinturas. Dessa forma, a definição de informação imagética não se encontra expressa nos textos, nem mesmo nos trabalhos que têm uma seção específica intitulada com tal terminologia. Mas foi possível perceber que os autores trazem à discussão a questão do tratamento de imagens, no âmbito da Ciência da Informação, para a sua organização e disponibilização aos usuários e para isso utilizam métodos e procedimentos para essas atividades.

\section{Considerações finais}

A utilização da imagem para a representação e a construção do conhecimento ocorre há muito tempo, desde a presença do homem no mundo. Tal fato intensificou-se com o desenvolvimento, a inserção e o aperfeiçoamento de novas tecnologias. Como exemplo, podemos citar, as mais variadas técnicas de gravura (litogravura, gravura em metal, xilogravura, entre outras), os diversos tipos de processos fotográficos desde o advento da fotografia, e o uso do computador. Essa realidade trouxe à tona questionamentos acerca do uso da imagem e da apropriação do seu conteúdo, o que resultou tanto em métodos descritivos como na elaboração de softwares para a sua disponibilização ao público usuário.

$\mathrm{O}$ presente texto teve como objetivo identificar e compreender como o conceito de informação imagética vem sendo utilizado no campo da Ciência da Informação no Brasil, e como foram formadas as suas bases fundamentais, sua abordagem e suas relações interconceituais, buscando expor quais foram as 
influências científicas para a construção desse conceito, a partir da análise de um conjunto de artigos. Assim, assevera-se que a ciência é construída por uma linguagem interna composta por seus códigos, métodos e técnicas; desse modo, percebeu-se que não há uma precisão conceitual para o entendimento de informação imagética na Ciência da Informação, pois não se constatou clareza e objetividade conceituais dessa terminologia.

Destarte, foi detectado que, embora os autores utilizem tal terminologia, as abordagens voltam-se apenas para o tratamento e a disponibilização das informações contidas nos documentos imagéticos. Dessa forma, o presente texto se constitui em um estudo exploratório sobre a temática para principiar uma discussão e instigar o desenvolvimento de futuras pesquisas que deem conta de uma construção conceitual sobre a informação imagética. Ademais, sobreleva-se a necessidade e importância de se ampliar o escopo dessa pesquisa para estudos futuros.

\section{Referências}

AGUSTÍN LACRUZ, Maria del Carmen. Análisis documental de contenido del retrato pictórico: propuesta epistemológica y metodológica aplicada a la obra de Francisco de Goya. Cartagena: 3000 Informática, 2006. (Tendencias; 3)

ANDERSON, John A.; BOWER, Gordon, H. A propositional theory of recognition memory. Memory \& Cognition, Austin, v. 2, n. 3, p. 406-412, 1974.

ARAÚJO, Carlos Alberto Ávila. O que é ciência da informação. Informação e Informação, Londrina, v. 19, n. 1, p. 1-30, jan./abr. 2014.

AUMONT, Jacques. A imagem. Campinas: Papirus, 1995.

AZEVEDO NETTO, Carlos Xavier de. A natureza da informação da arte rupestre: a proximidade de dois campos. Informare - Cadernos do Programa de Pós-graduação em Ciência da Informação, Rio de Janeiro, v. 4, n. 2, p. 55-62, 1998.

AZEVEDO NETTO, Carlos Xavier de; FREIRE, Bernardina Maria Juvenal; PEREIRA, Perpétua Emília Lacerda. A Representação de Imagens no Acervo da Biblioteca Digital Paulo Freire - Proposta e percursos. Ciência da Informação, Brasília, v. 33, n. 3, p. 17-25, 2004.

BARROS, Kelly Cristiane Queiroz; AZEVEDO NETTO, Carlos Xavier. O acervo fotográfico de José Simeão Leal: representação da informação imagética 
e descrição de redes de sociabilidade. In: MOTA, Ana Roberta Sousa; GALVINO, Claudio Cesar Temóteo; GASQUE, BARROS, Kelly Cristiane Queiroz; LLARENA, Rosilene Agapito da Silva; LIRA, Suzana de Lucena Lira. (Org.). Versados em ciência da informação. João Pessoa: Imprell, 2014. cap. 9.

BECKER, Howard Saul. Métodos de pesquisa em ciências sociais. Tradução de Marco Estevão e Renato Aguiar. São Paulo: HUCITEC, 1993. 230 p.

BITTENCOURT, Luciana Aguiar. Algumas considerações sobre o uso da imagem fotográfica na pesquisa antropológica. In: FELDMAN-BIANCO, Bela; LEITE, Miriam Lifchitz Moreira. (Orgs.). Desafios da imagem: fotografia, iconografia e vídeo nas ciências sociais. Campinas: Papirus, 1998. p. 197-212.

BRIET, Suzanne. Qu'est-ce que la documentation? Paris: Éditions Documentaires Industrielles et Técnicas, 1951.

BUCKLAND, Michael Keeble. Information as thing. Journal of the American Society forInformation Science, v. 45, n. 5, p. 351-360, 1991.

CAÑADA, J. Tipologías y estilos en el etiquetado social. Terremoto.net: diseño de interacción desde el año 2000. 2006.

DAHLBERG, Ingetraut. Ontical structure and universal classifi cations. Bangalore: Sarada Ranganathan Endowment for Library Science, 1978a. 64 p.

FIGUEIREDO, Márcia Feijão de. Pós-fenomenologia e Ciência da Informação: aportes epistêmicos para acesso ao conhecimento. Incid, Ribeirão Preto, v. 3, n.1, p. 21-35, jan./jun. 2012.

FINKE, Ronald A. Principles of mental imagery. The American Journal of Psychology, Champaign, v. 104, n. 3, p. 460-463. 1991.

FOSKETT, Antony Charles. A abordagem temática da informação. São Paulo: Polígono, 1973.

GIL, Antônio Carlos. Como elaborar projetos de pesquisa. 3. ed. São Paulo: Atlas, 1991.

GONÇALVES, Eveline Filgueiras; OLIVEIRA, Rafael Alves de; NEVES, Dulce Amélia de Brito. Análise da informação imagética: uma abordagem sob a perspectiva cognitiva. Em Questão, Porto Alegre, v. 22, n. 3, 2016.

HALBWACHS, Maurice. A memória coletiva. São Paulo: Centauro, 2006.

HJØRLAND, Birger; ALBRECHTSEN, Hanns. Toward a new horizon in information science: domain analysis. Journal of the American Society of Information Science, [s.l.], n. 46, v. 6, 1995, p. 400-425. 
IHDE, Don. Bodies in technology. Minneapolis: Minnesota Press, 2002.

KOSSOY, Boris. Fotografia e história. São Paulo: Ateliê Editorial, 2001.

KUHN, Thomas Samuel. A estrutura das revoluções científicas. São Paulo: Perspectiva, 1998.

LACERDA, Aline Lopes. Os sentidos da imagem: fotografias em arquivos pessoais. Acervo: Revista do Arquivo Nacional, Rio de Janeiro, v. 6, n. 1-2, p. 41-54, jan./dez. 1993.

LE GOFF, Jacques. História e memória. Campinas: UNICAMP, 1990.

MAIMONE, Giovana Deliberali; GRACIOSO, Luciana de Souza. Representação temática de imagens: perspectivas metodológicas. Informação \& Informação, Londrina, v. 12, n. 1, p. 1-12, 2007.

MAIMONE, Giovana Deliberali; TÁLAMO, Maria de Fátima Gonçalves de Moreira. Tratamento informacional de imagens artístico-pictóricas no contexto da Ciência da Informação. DataGramaZero, Rio de Janeiro, v. 9, n. 2, abr. 2008.

MAIMONE, Giovana Deliberali; TÁLAMO, Maria de Fátima Gonçalves Moreira. Metodologias de representação da informação imagética.

Transinformação, Campinas, v. 21, n. 3, p. 181 - 196, 2009.

MANINI, Miriam Paula. Análise documentária de imagens. Informação \& Sociedade: Estudos, João Pessoa, v. 11, n. 1, p. 1-5, 2001.

MANINI, Miriam Paula. Análise documentária de fotografias: um referencial de leitura de imagens fotográficas para fins documentários. 2002. Tese (Doutorado em Ciências da Comunicação) - Universidade de São Paulo, São Paulo, 2002.

NÓBREGA, Isabella de Oliveira; MANINI, Miriam Paula. \#impeachment ou \#naovaitergolpe: uma análise sobre a folksonomia na indexação de imagens fotográficas em redes sociais da Web 2.0. Biblionline, João Pessoa, v. 12, n. 4, p. $73-84,2016$.

NÖTH, Winfried; SANTAELLA, Lúcia. Imagem: cognição, semiótica, mídia. São Paulo: Iluminuras, 1998.

ORTEGA, Cristina Dotta; LARA, Marilda Lopes Ginez de. Documento e informação, conceitos necessariamente relacionados no âmbito da ciência da informação. In: ENCONTRO NACIONAL DE PESQUISA EM CIÊNCIA DA INFORMAÇÃO, 9, 2008. São Paulo, Anais [...]. São Paulo, USP, 2008.

OTLET, Paul. Traité de Documentation - Le livre sur le Livre - Théorie et Patique. Bruxeles: Editiones Mundaneum. 1934. 
PAIVIO, Allan. Mental imagery in associative learning and memory.

Psychological Review, Washington, v. 76, n. 3, p. 241-263, 1969.

PANOFSKY, Erwin. Significado nas artes visuais. São Paulo: Perspectiva, 1979.

PEIRCE, Charles Sanders. Semiótica. São Paulo: Perspectiva, 1985.

RODRIGUES, Ricardo Crisafulli. Análise e tematização da imagem fotográfica. Ciência da Informação, Brasília, v. 36, n. 3, p. 67-76, set./dez. 2007.

SARACEVIC, Tefko. Ciência da Informação: origem, evolução e relações.

Perspectivas em Ciência da Informação, Belo Horizonte, v. 1, n. 1, p. 41-62, jan./jun. 1996.

SMIT, Johanna. Wilhelmina. Análise documentária: a análise da síntese. Brasília: IBICT, 1987. 133 p.

SMIT, Johanna Wilhelmina. A representação da imagem. Informare, Rio de Janeiro, v. 2, n. 2, p. 28-36, jul./dez. 1996.

SMIT, Johanna Wilhelmina. A documentação e suas diversas abordagens. In: GRANATO, Marcus; SANTOS, Claudia. Penha; LOUREIRO, Maria Lucia; NIEMEYER Matheus (orgs.). Documentação em museus. Rio de Janeiro: MAST, 2008.

SOUSA, Lucília Maria Abrahão; FUJITA, Mariângela Spotti Lopes; GRACIOSO, Luciana de Souza. A imagem na ciência da informação. São Paulo: Oficina Universitária, 2014.

SHATFORD, Sara. Describing a picture: a thousand words are seldom cost effective. Cataloging \& Classification Quarterly, New York, v. 4, n. 4, p. 1330, Summer 1984.

STERNBERG, Robert J. Representação do conhecimento: imagens e proposições. In: STERNBERG, Robert J. Psicologia cognitiva. Porto Alegre: Artmed, 2000.

TARGINO, Maria das Graças. Comunicação científica: o artigo de periódico nas atividades de ensino e pesquisa do docente universitário brasileiro na pósgraduação. 1998. Tese (Doutorado em Ciência da Informação) - Faculdade de Estudos Sociais Aplicados, Universidade de Brasília, Brasília, 1998.

TORRES, Simone; ALMEIDA, Maurício Barcellos. O conceito de documento na ciência da informação e arquivologia. In: ENCONTRO NACIONAL DE PESQUISA EM CIÊNCIA DA INFORMAÇÃO, 14., 2013, Florianópolis. Anais [...]. Florianópolis: UFSC, 2013. 


\title{
The concept of imagery information in information science: theoretical and conceptual approximations
}

\begin{abstract}
The conceptions about information have passed by changes due to the studies developed for its organization, use and availability. From this assertive, it is considered that this transformation process was based on ideas and thoughts that fundamentally passed by the concepts of document and study object of Information Science, information itself. Theoretical currents and paradigms were built and reformulated, above all, when directed to imagery documents. In this sense, the present paper is intended to apprehend, from an exploratory research in the database of journals in Information Science (Base de dados de Periódicos em Ciência da Informação), how the concept of imagery information is being used in Brazil field of Information Science. Thus, it is asseverated that science is built by an internal language which is composed by its codes, methods and techniques and, in this sense, it is perceived in this study that there is no conceptual precision to the understanding of imagery information in Information Science, once it is not perceived a conceptual clarity and objectivity for this terminology. In addition, the need and importance of expanding the scope of this research for future studies from the analysis of the annals of scientific events in the area of Information Science and of the databases of theses and dissertations hat were not here contemplated.
\end{abstract}

Keywords: Information. Image. Information Science. Imagery information.

Recebido: 22/05/2018

Aceito: $13 / 11 / 2018$

\footnotetext{
${ }^{1}$ Adota-se o conceito de imagem como representação visual de um dado objeto, podendo ser: pinturas, gravuras, fotografias, audiovisuais, projeções e mentais; nesse sentido, o meio que a construiu é o mais diverso. (NÖTH, SANTAELLA, 1998).

${ }^{2}$ A BRAPCI é uma base de dados que indexa artigos de periódicos sobre a produção acadêmica na área da Ciência da Informação. Assim, optou-se por analisar apenas os artigos de periódicos devido ao seu impacto e reconhecimento numa dada área do conhecimento, pois o mesmo se constitui em uma fonte informacional com diversas finalidades, entre elas, a produção e disseminação da ciência.

${ }^{3}$ De acordo com levantamento realizado na Base de Dados e nos anais do ENANCIB, em 2016. Esses dados ainda não foram publicados.
} 